\title{
O retrato da violência no romance Piedras Encantadas (2001), de Rodrigo Rey Rosa: uma construção estética
}

DOI: https://doi.org/10.22409/pragmatizes.v10i18.38871

\section{Rodrigo de Freitas Faqueri ${ }^{1}$}

Resumo: Este artigo traz à tona um olhar sobre a literatura centro-americana a partir de um estudo realizado sobre o romance, Piedras encantadas (2001), do escritor guatemalteco contemporâneo Rodrigo Rey Rosa. Neste romance, percebe-se a construção do espaço a partir da violência, seja representativa, seja textual, seja pelos personagens que se fazem presentes nas descrições realizadas, seja pela escolha do léxico ou pela carga histórica ali inserida, retratando uma Guatemala construída e alicerçada em vários âmbitos da violência.A escrita de Rey Rosa se diferencia pela abordagem particular quanto à utilização da violência com a perspectiva de que, em seus textos, a violência não é só um elemento de discussão que faz o leitor refletir sobre ela, mas que viabiliza a construção da narrativa a partir de seus traços peculiares acrescidos de outros aspectos presentes na obra. Como referencial teórico, este artigo se debruça nos estudos realizados pelo chileno Ariel Dorfman (1972) sobre algumas dimensões da violência na literatura e as explanações de Schøllhammer (2013) sobre esse assunto.

Palavras-chave:Violência;Espaço; Rey Rosa; Guatemala.

El retrato de la violencia en la novela Piedras Encantadas (2001), de Rodrigo Rey Rosa: una construcción estética

Resumen: Este artigo evidencia una mirada sobre la literatura centroamericana a partir de un estudio realizado sobre la novela, Piedras encantadas (2001), del escritor guatemalteco contemporáneo Rodrigo Rey Rosa. En esta novela, se nota la construcción del espacio a partir de la violencia, sea representativa, sea textual, sea por los personajes que están presentes en las descripciones realizadas, sea por la elección de léxico o por la carga histórica inserida, retratando una Guatemala construida y cimentada en varios ámbitos de la violencia. La escrita de Rey Rosa se diferencia por el abordaje particular cuanto a la utilización de la violencia con la perspectiva de que, en sus textos, la violencia no es solo un elemento de discusión que hace el lector reflexionar sobre ella, pero que viabiliza la construcción de la narrativa a partir de sus rasgos peculiares acrecidos de otros aspectos presentes en la obra. Como referencial teórico, este artículo se inclina hacia los estudios realizados por Ariel Dorfman (1972) sobre algunas dimensiones de la violencia en la literatura y las explanaciones de Schøllhammer (2013) sobre dicho tema.

Palabras clave: Violencia; Espacio; Rey Rosa; Guatemala.

\footnotetext{
${ }^{1}$ Rodrigo de Freitas Faqueri. Doutor em Letras. Professor do Instituto Federal de Educação, Ciência e Tecnologia de São Paulo (IFSP), Brasil. E-mail: rodrigofaqueri@hotmail.com.
} 
The portrayal of violence on Rodrigo Rey Rosa's Piedras Encantadas (2001): an aesthetics construction

\begin{abstract}
This article brings up a look on Central America literature, based on a study of the book Piedras Encantadas (2001), from the contemporary Guatemalan writer Rodrigo Rey Rosa.In this romance, it is observed the construction of space from the perspective of violence, either representative, textual, from the characters that are present on the descriptions made, by the lexicon choice or by historical facts inserted in the work, portraying a Guatemala built and rooted in various scopes of violence. The writing of Rey Rosa is singular by his particular approach on the use of violence with the perspective that, in his writings, the violence is not only an element for discussion that makes the reader reflect about it, but it also enables the construction of the narrative from its peculiar traces bolstered by other aspects of the work. As theorical framework, this article elaborates on studies from Chilean author Ariel Dorfman (1972) about dimensions of violence in literature and explanations from Schøllhammer (2013) about this subject.
\end{abstract}

Keywords: Violence; Space; Rey Rosa; Guatemala.

\title{
O retrato da violência no romance Piedras Encantadas (2001), de Rodrigo Rey Rosa: uma construção estética
}

\section{Introdução}

No começo dos anos 1990, a chamada "pacificação" dos países centro-americanos teve como marco a derrota eleitoral do governo revolucionário sandinista na Nicarágua, que havia destituído por meio de luta armada o ditador Anastasio Somoza em 1979. Ao assumir o poder na década de 1980 a Frente Sandinista de Libertação Nacional (FSLN), com Daniel Ortega como líder, revogou a Constituição, dissolveu o Congresso e substituiu a Guarda Nacional pelo Exército Popular Sandinista. Todas essas ações geraram revolta por parte de outros grupos que eram contra tais medidas e desencadearam uma série de conflitos armados entre o Exército Sandinista e os "Contras", grupo contrário às ações governamentais da época. Em 1988, Ortega assina uma lei de reforma eleitoral, prevendo eleições amplas e livres em 1990. Nesse ano, Violeta Barrios de Chamorro vence as eleições presidenciais e inicia, então, o processo de pacificação no país.

Seguiram, cronologicamente esse processo, a assinatura dos Acordos de Paz em El Salvador (1992) e na Guatemala (1996). Neste último, o acordo assinado põe fim à guerra civil que durou 36 anos e deixou mais de centenas de milhares de mortos, dezenas de milhares de desaparecidos 
e um genocídio dos descendentes do povo maia na década de 1980 ainda em investigação até hoje. Os anos que seguem, trazem à tona uma política de reconstrução da democracia e do desenvolvimento para esta área. Para Ortiz Wallner (2012, p. 31),

Esos años de transición se han
caracterizado, sin embargo, por ser
un momento matizado por una
cultura de la discriminación y la
violencia, así como por la
profundización de las crisis y
exclusión sociales. ${ }^{2}$

Esses anos de transição aos quais a autora se refere no trecho anterior são marcados por uma escrita que reflete o desencanto e a frustração da população centro-americana com relação às revoluções acontecidas no período anterior que trouxeram uma promessa de mudança para a região e criaram uma esperança nos discursos ali proferidos.

$\mathrm{Na}$ literatura, esse período de transição do fim dos anos oitenta e início dos anos noventa, com o fim das guerras anteriormente citadas, apareceram as narrativas que foram

2 Esses anos de transição foram caracterizados, entretanto, por ser um momento matizado por uma cultura da discriminação e pela violência, assim como pelo aprofundamento da crise e a exclusão sociais. (Tradução nossa) denominadas de literatura de pósguerra. Os relatos e as narrativas de testemunho produzidas durante quase toda a segunda metade do século $X X$ já não conseguem mais dar voz aos sentimentos da população centroamericana e surge a necessidade de se falar de algo latente, visível e assustador que se apresenta diante dos olhos de todos. Uma realidade pós-guerra que emerge mais rápida que a reconstrução anunciada e a redemocratização pretendida.

Existe, neste ponto, uma mudança estética nas narrativas centro-americanas. Sai-se da militância política para buscar-se uma estética que não almeja mais 0 universal, mas 0 individual. $A$ identidade centro-americana também segue sendo buscada e construída, porém não mais pela ótica das revoluções e dos conflitos armados iniciados nos anos 1960 e intensificados nas décadas de 1970 e 1980. Neste cenário, esta identidade vai sendo percebida a partir das novas temáticas que são abordadas: a morte, a violência urbana, cotidiana e gratuita, as feridas/marcas das recentes guerras, a solidão, a frustação, entre outras, que apontam para uma 
literatura de desencanto (CORTEZ, 2010).

A literatura que se elabora a partir desse instante reage contra a estética criada pela literatura testemunhal. Surge uma escrita voltada para as acusações sociais, mas com grande experimentalismo estético. A literatura de pós-guerra traz uma mudança em relação ao conceito daquilo que é o nacional assim como as propostas de solidificação do caráter nacional, as relações fronteiriças e os processos culturais, que são híbridos.

O fim do século XX e o início do XXI são marcados pelo aprofundamento de temáticas como os relatos de violência cotidiana, a violência e o pânico propagado pela formação e 0 crescimento das gangues, o fluxo migratório incessante em busca de melhores condições de vida e também relatos de personagens que atravessam circunstâncias cotidianas consideradas estranhas ou incomuns, carregadas, em alguns casos, de um teor fantástico.

Fato é que, também, se o panorama histórico centro-americano for analisado com maior profundidade, não se terá uma percepção comum ou genérica de tudo o que aconteceu nesses países. A literatura se encarga de evidenciar uma Centroamérica que se encontra à mercê dos príncipes dos carteis do narcotráfico, das maras, ou dos Zetas - grupos de pessoas que se aproveitam de milhares de imigrantes pobres que buscam atravessar a fronteiras ilegalmente. Essas situações do cotidiano centro-americano não são passageiras apesar de todas serem incorporadas de maneira natural à vida desses habitantes.

A literatura centro-americana e a estética da violência

Nesses países, a narrativa produzida pelos autores contemporâneos $^{3}$ se faz valer da necessidade de reconstruir e evidenciar o cenário de tal nação assim como a de organizar a condição humana devastada e perseguida pelas sombras de um passado tenebroso. Escamilla (2011, p. 19) aponta um novo espaço cultural em que as fronteiras se diluem e a

\footnotetext{
${ }^{3}$ Alguns nomes desta geração contemporânea são Róger Lindo, Jacinta Escudos e Castellanos Moya (salvadorenhos); Franz Galich, Otoniel Martínez, Rafael Cuevas Molina e Danto Liano (guatemaltecos); Omar Cabezas, Sergio Ramírez e Gioconda Belli (nicaraguenses).
} 


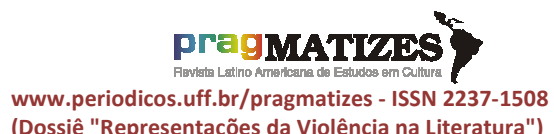

(Dossiê "Representações da Violência na Literatura") imprescindibilidade de se narrar o que se vive em diferentes locais simultaneamente tomam a dianteira da narrativa centro-americana. $\mathrm{O}$ autor afirma também que cresce o a caráter da individualidade para mostrar o panorama social centro-americano contemporâneo:

De estas individualidades unas adquieren el rostro de la violencia, otras de la indiferencia y la desilusión que encarnan los personajes novelescos para retratar esos signos que en la cotidianidad tienen nombre y apellido. (ESCAMILLA, 2011, p. $19)^{4}$

Escamilla (2011, p. 23) destaca também que para compreender a literatura centro-americana produzida pós-guerra é necessário entender que esta é produção de um processo sociocultural e que quem a produz ou a lê também pertence à sociedade que está sendo retratada. Não é uma visão externa ou afastada da situação que está acontecendo, mas uma observação in loco das consequências do processo histórico sofrido por toda a região.

No início da década de 1990, como já apontado, a narrativa centro-americana

\footnotetext{
4 Destas individualidades umas adquirem 0 rosto da violência, outras da indiferença e a desilusão que encarnam as personagens romanescas para retratar esses signos que na cotidianidade têm nome e sobrenome. (Tradução nossa)
}

se transforma em um "espaço" no qual a própria literatura se mostra com características relacionadas à violência em diversos graus e expressões:

La narrativa centroamericana a partir de la década de 1990 [...] tiene de relacionarse con la violencia en tanto que dinamiza las dimensiones de las representaciones, las reacciones y los desplazamientos de la violencia en sus más diversas facetas hasta convertirse en un acto de violencia. Está claro que el corpus de esta literatura permanece abierto, y que incluye una gran cantidad de autores, obras y tipos de textos, desde sex, drugs and (no, no rock'n roll, sino) salsa hasta la novela negra y la novela policiaca, una forma cada vez más popular en la región, siendo su cercanía con los medios masivos más que evidente en cuanto a lo que a las técnicas narrativas se refiere. (MACKENBACH; ORTIZ WALLNER, 2008, p. 10) ${ }^{5}$

Dentro deste cenário centroamericano contrastivo e tenso surgem autores que pretendem mostrar um retrato contundente de seus países e de suas realidades, agregando um novo estilo em sua narrativa que, por sua vez, é marcado em algumas ocasiões pela precisão e pela

5 A narrativa centro-americana a partir da década de 1990 [...] tem de relacionar-se com a violência de tal maneira que dinamiza as dimensiones das representações, as reações e os deslocamentos da violência em suas mais diversas facetas até se converter em um ato de violência. Está claro que o corpus desta literatura permanece aberto, e que inclui uma grande quantidade de autores, obras e tipos de textos, desde sex, drugs and (não, não rock'n roll, mas sim) salsa até o romance negro e o romance policial, uma forma cada vez mais popular na região, sendo sua aproximação com os meios massivos mais que evidente quanto ao que às técnicas narrativas se refere. (Tradução nossa) 
agilidade e, em outras, pela imagem da cidade como locus terribilis onde todos os pesadelos se concentram nela e se questiona como é possível sobreviver em um ambiente tão inóspito (MACKENBACH; ORTIZ WALLNER, 2008).

Confluindo com a ideia proposta por Escamilla aponta-se o pensamento de Ortiz Wallner (2003), que já havia destacado que a estética literária centro-americana não estaria mais centrada em acontecimentos políticos nem preocupada em retratar datas e fatos históricos, mas suas transformações começam a ser, neste momento, atreladas a processos culturais complexos, provenientes de diversos fatores. Começa-se a ser construída, então, uma mentalidade de se mostrar a nova realidade nacional e regional a partir de novas estratégias de escrita que percorrem o cenário e as indagações atuais:

[...] por un lado, la incorporación de elementos de la cultura popular urbana que aparece muchas veces vinculada a la sátira, el humor y la ironía, estrategias que apuntan a la particular importancia que se le otorga a la oralidad y a su escenificación en los textos escritos. Por otro lado, destaca en un amplio corpus narrativo la presencia de diversos elementos propios de la novela policiaca tradicional y de la novela negra, como el motivo del crimen y la presencia/ausencia del detective, que son constantemente subvertidos y parodiados. También podemos mencionar una presencia destacada de los mass media como la televisión, la radio y la prensa (especialmente la prensa amarillista). (MACKENBACH; ORTIZ WALLNER, 2008 , p. 8$)^{6}$

Assim, surge a ideia da "cultura da violência"e a "estética da violência"que se propõe destacar neste artigo. Tem-se como definição da expressão cultura da violência como o legado histórico da violência e sua consequente naturalização na dinâmica cotidiana de um determinado lugar ou país. Reconhecem-se a impunidade generalizada, 0 autoritarismo vigente e constante, a militarização da cultura cidadã, um sistema judiciário fraco e inoperante que se manifesta a partir das próprias ações do Estado e em sua relação com a população e que gera uma "cultura do silêncio" exatamente pela

6 [...] por um lado, a incorporação de elementos da cultura popular urbana que aparece muitas vezes vinculada à sátira, ao humor e à ironia, estratégias que apontam para a particular importância que se the outorga à oralidade e à sua encenação nos textos escritos. Por outro lado, destaca em um amplo corpus narrativo a presença de diversos elementos próprios do romance policial tradicional e do romance negro, como o motivo do crime e a presença/ausência do detetive, que são constantemente subvertidos $e$ parodiados. Também podemos mencionar uma presença destacada dos mass media como a televisão, o rádio e a imprensa (especialmente a imprensa marrom). (Tradução nossa) 
ineficiência do sistema forense, pela violência praticada pelo poder executivo e pela resposta negativa da própria população a todos esses acontecimentos (CUEVAS MOLINA, 2012, p. 147).

Nesta perspectiva, a violência acaba se tornando uma das maneiras viáveis de resposta imediata aos conflitos encontrados na sociedade. Assim, responde-se à violência cotidiana a que alguém está submetido com a própria violência sofrida para se defender ou reagir à primeira violência exposta. Põem-se nos dois lados da moeda a mesma marca e a exata igualdade entre os signos.

Seguindo este pensamento, consegue-se observar que as narrativas centro-americanas vêm sendo construídas por meio de diversos elementos que costumam representar uma violência estrutural direta/indireta e que a dinâmica da produção narrativa a partir da década de 1990 busca interagir profundamente com os exemplos de manifestações da violência cotidiana em determinadas partes da região:

En forma directa y breve se muestran múltiples elementos que pueden ser recorridos como constantes dentro de la producción narrativa centroamericana que emerge a partir de la década de 1990 y que pueden organizarse dinámicamente desde la interacción de al menos las siguientes dimensiones: las representaciones de la violencia, las reacciones ante la violencia, los desplazamientos de la violencia y la literatura como violencia. (MACKENBACH; ORTIZ WALLNER, 2008, p. 82) ${ }^{7}$

Pensando na literatura como plataforma de manifestação possível da violência, conforme exposto pelos autores, dimensiona-se o conceito da estética da violência, pois a violência neste momento não é somente mais uma temática, mas também é parte de um elemento da construção narrativa presente nos textos produzidos em certos países da América Central, principalmente na Guatemala e em El Salvador, a partir de 1990. Walter Benjamin (1985) foi um dos primeiros a chamar a atenção das democracias ocidentais para o perigo da "estética na política". Para o autor, quando Hitler encomendou filmes sobre a Alemanha e sobre a SS, o Führer transformou os aspectos estéticos existentes na política e incorporou uma nova definição ao termo em questão.

\footnotetext{
7 De forma direta e breve são mostrados múltiplos elementos que podem ser observados como constantes na produção narrativa centro-americana que emerge a partir da década de 1990 e que podem ser organizados dinamicamente a partir da interação de ao menos as seguintes dimensões: as representações da violência, as reações ante a violência, os deslocamentos da violência e a literatura como violência. (Tradução nossa)
} 
A mesma configuração é entendida quanto à estética da violência, pois a barbárie se tornou natural e milhões puderam expor seus instintos selvagens sem consciência de culpa. Atualmente, a estética da violência sobrevive e possui grande força. Não mais como um ritual cruel de genocídios e extermínios ao som de canções populares, mas também estetizados pelos media. A imprensa em geral e a televisão "mercantilizam" a violência como um produto racionalmente vendável, da mesma forma, sem consciência de culpa. O horror, a destruição, as mutilações, etc. se tornaram um bom prato para um público sedento por sangue. Assim, na estética da violência, a própria violência se desloca, segundo Ortiz Wallner (2003, p. 140):

hacia el espacio existencial, hacia el uso de un lenguaje que arremete contra el lector y a la utilización de "estrategias escriturales" que rompen los órdenes tradicionales en el nivel formal. Se trata de una estética que pretende resolverse en una agresividad que da la impresión de ser gratuita. ${ }^{8}$

\section{É importante destacar que a} violência já aparece na literatura há séculos como objeto de estudo e temática

\footnotetext{
${ }^{8}$ Em direção ao espaço existencial, ao uso de uma linguagem que arremete contra o leitor $e$ à utilização de "estratégias escriturais" que rompem as ordens tradicionais no nível formal. Trata-se de uma estética que pretende resolver-se em uma agressividade que dá a impressão de ser gratuita. (Tradução nossa)
}

recorrente e que, dentro da cosmovisão e da estrutura social latino-americana, a violência está intrínseca como manifestação concreta. Segundo Schøllhammer, "é uma chave para entender a cultura e parece ser um dos fundamentos da própria estrutural social." (2013, p.103). O autor ainda apresenta a ideia da violência como um fenômeno social marginal transgressivo dentro de uma ordem social autoritária em um contexto literário construído nas primeiras décadas do século XX.

A partir da segunda metade do século $\mathrm{XX}$, principalmente com os textos do chileno Ariel Dorfman ${ }^{9}$, encontram-se algumas dimensões da violência dentro da literatura. Schøllhammer explana sobre essas dimensões proporcionando 0 seguinte entendimento: a primeira dimensão se refere à violência social, como uma matriz vertical, que possui as faces de repressora e autoritária ou rebelde e libertadora que vê na literatura a abertura para ser simbolizada como um processo de redenção e a retomada da honra e uma libertação dos mecanismos opressores. Na segunda dimensão, que estaria em uma posição horizontal, está a violência intersubjetiva que está atrelada ao caráter individual, beirando a solidão ou a alienação deste indivíduo em destaque. Nessa dimensão, a demanda

\footnotetext{
9 Imaginación y violencia en América Latina
} (1972). 
existencial se faz presente a partir dos modelos de honra e vingança, provocando uma condição humana de isolamento. $O$ agravamento dessa segunda dimensão seria dentro de um âmbito interior e psicológico, atando a violência à angústia e ao desespero que não é (ou não pode ser) externalizado. A quarta dimensão apresenta características da violência como representação:

Finalmente, Dorfman inclui a violência da representação, vendo na literatura um movimento transgressivo de ruptura que possa produzir um efeito contundente de choque com um desenlace semelhante à experiência catártica de purificação das emoções por terror e piedade. Assim, parece haver uma presença da violência na literatura não só na representação temática de uma violência, mas também na exploração pela escrita de efeitos sensíveis que desloca a fronteira do que pode ou não ser dito. Pode-se entender a violência da representação nessa perspectiva ligada à dimensão expressiva e performática da literatura, capaz de mudar as fronteiras do que pode ser representado ou não, do que pode ser escrito ou não, abrindo assim caminho para um reconhecimento dinâmico através da ficção do que é real ou não. A violência perfomativa agencia na literatura a fronteira entre a realidade e a ficção ao abrir a possibilidade de reconhecer realidades antes não experimentadas e rompendo certezas do que é real. (SCHØLLHAMMER, 2013, p. 107)

É a partir desta última dimensão, e buscando-se ir mais além, que se propõe uma estética que aborda a violência não só como temática recorrente que permeia as obras literárias latino-americanas contemporâneas. A teoria que se apresenta neste artigo é de que a violência possui um caráter performático representado em um estilo de escrita, nos recursos e nas escolhas linguísticas feitas por um autor. Não se trata de evidenciar a violência pautando-se nas outras dimensões citadas, conferindo-Ihe uma posição dentro de uma categoria temática, mas de revelá-la a partir de um projeto estético-linguístico-literário que rompe com ideal inicial e vai mais além, perpetrando a violência na escrita como forja para um novo projeto estilístico. Trata-se de utilizar a violência como matéria-prima temática e estrutural para a literatura, conforme aponta Schøllhammer (2013, p. 108-109):

Se a literatura privilegia a violência como tema e matéria-prima, é porque a literatura penetra na violência exatamente naquilo que escapa aos outros discursos apenas representativos, naquilo que é o elemento produtivo e catalisador na violência e a faz comunicar. É certo que a violência pode ser entendida como o limite da comunicação, o ponto em que as palavras se rendem ao silêncio da força bruta e em que o diálogo de certa maneira é eclipsado pelo poder. Por outro lado, a violência também pode ser o ponto inicial de uma comunicação, uma imposição que força relações de poder engessadas a reformularem. Para a literatura, e principalmente para a narrativa ficcional, o elemento produtivo gira em torno da imaginação injetada pela violência e a natureza enigmática de sua realidade íntima e cruel. 
Assim, entende-se que a literatura centroamericana contemporânea se faz valer da estética que privilegia a escrita não só da violência, mas também, principalmente, pela violência. É a construção de um estilo que encontra na violência um campo de experiência criativa que transborda os limites literários dos discursos literários já conhecidos.

Esse novo projeto literário centroamericano contemporâneo é contemplado por Ortiz Wallner quando a autora afirma que não se encontra mais uma denúncia da opressão sofrida na região, que se mantinha pela ideia de força na luta armada e na violência justificada politicamente, mas surge um modelo estético diferente.

[...] que una gran parte de estos textos literarios van a privilegiar una mirada inquisidora y crítica sobre las consecuencias de las múltiples relaciones de violencia en y entre los individuos $y$ en sus relaciones interpersonales. Se trata de textos literarios que cuestionan las (im)posibilidades de (sobre)vivir en espacios de violencia, predominando en ellos lo que Dante Liano describe como "violencia oblicua", es decir, aquel espacio textual en el cual la violencia está contenida de manera indirecta, sumergida, alegórica, lo que hace que la narración sea una donde la denuncia social directa ya no aparece [...]. Las realidades e historias de violencia ficcionalizadas en las narrativas centroamericanas recientes se articulan así en una presencia velada y sumergida de la violencia, por ejemplo en el lenguaje y las estructuras narrativas. (ORTIZ WALLNER, 2015, p. 320-321) ${ }^{10}$

É exatamente na linguagem e nas estruturas narrativas construídas por Rodrigo Rey Rosa que aparece esta nova estética da violência que prioriza a produção escrita dentro de uma perspectiva singular a fim de dar novos sentidos à produção literária cernida em uma nova escritura da violência. Sendo um projeto literário diferente daquele produzido nas décadas de 1960 e 1970, esta estética busca trazer a violência de diversas formas, como menciona a autora, indireta, submergida, alegórica, utilizando outras técnicas para fazer surgir um espaço pautado na construção imagética da violência.

\footnotetext{
${ }^{10}[\ldots]$ que uma grande parte destes textos literários vão privilegiar um olhar inquisidor e crítico sobre as consequências das múltiplas relações de violência no e entre os indivíduos e em suas relações interpessoais. Tratam-se de textos literários que questionam as (im)possibilidades de (sobre)viver em espaços de violência, predominando neles o que Dante Liano descreve como "violência oblíqua", ou seja, aquele espaço textual no qual a violência está contida de maneira indireta, submergida, alegórica, o que faz [com] que a narração seja uma onde a denúncia social direta já não aparece [...]. As realidades e histórias de violência ficcionalizadas nas narrativas centroamericanas recentes se articulam assim em uma presença velada e submergida da violência, por exemplo na linguagem e nas estruturas narrativas. (Tradução nossa)
} 


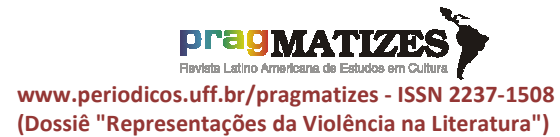

Além disso, assim como em El Material Humano(2009) e em Los Sordos (2012), outras obras importantes do autor, tem-se o retrato da vida urbana na capital guatemalteca e, neste caso, uma frustração pelos problemas latentes desta sociedade recém-saída de uma guerra civil de trinta e seis anos de duração. O prefácio da narrativa apresenta uma Guatemala repleta de elementos desencantadores que refletem a desesperança quanto a possíveis mudanças em um futuro próximo: senhora está em pleno processo de divórcio e o seu esposo é um homem que ascendeu rapidamente nos negócios. A narrativa, entretanto, não se compõe linearmente como um relato das experiências e das descobertas desta personagem investigadora, mas se fragmenta e direciona o leitor para cenas aparentemente secundárias que, ao final, acabam por tecer juntas uma rede de histórias interconectadas por detalhes para construir o desfecho. Desse modo, Piedras encantadas (2001) é um romance muito curto, mas que atua como ponto de condensação da problemática guatemalteca e suas diversas formas de violência.
Guatemala, Centroamérica.

El país más hermoso, la gente más fea.

Guatemala. La pequeña república donde la pena de muerte no fue abolida nunca, donde el linchamiento ha sido la única manifestación perdurable de organización social.

Ciudad de Guatemala. Doscientos kilómetros cuadrados de asfalto y hormigón (producido y monopolizado por una sola familia durante el último siglo). Prototipo de la ciudad dura, donde la gente rica va en blindados y los hombres de negocios más exitosos llevan chalecos antibalas. [...]

[...] Para subir al décimo piso de una <<torre>> - estás en el sector privilegiado - tomas el elevador. (Pero hoy no funciona.)

Aquí (casi) nada es como piensas. [...]

No olvides que estás en Guatemala. [...] Dicen que en una de las casetas venden polvo de coca y piedras de crack. Más vale no 
protestar. (REY ROSA, 2014, p. 209$210)^{11}$

Os trechos acima retirados do prefácio da obra são alguns exemplos da frustração da personagem Joaquín Casasola de voltar a viver novamente na Guatemala depois de anos morando na Espanha. Mais do que isso, a citação revela um cenário desanimador a partir da perspectiva de um nativo dentro de seu próprio país.

Sendo escrito mais de dez anos antes de Los Sordos (2012), o prefácio de Piedras encantadas (2001) constrói um ambiente que ainda estaria presente no romance publicado uma década mais tarde. A questão dos linchamentos dentro da sociedade guatemalteca é destacada nos dois

11 Guatemala, América Central.

O país mais lindo, a gente mais feia.

Guatemala. A pequena república onde a pena de morte não foi abolida nunca, onde o linchamento tem sido a única manifestação perdurável de organização social.

Ciudad de Guatemala. Duzentos quilômetros quadrados de asfalto e concreto (produzido e monopolizado por uma só família durante o último século). Protótipo da cidade difícil, onde a gente rica vai dentro de carros blindados e os homens de negócios mais bem-sucedidos usam coletes à prova de balas. [...]

[...] Para subir até o décimo andar de uma <<torre>> - está no setor privilegiado - você pega o elevador. (Mas hoje ele não funciona.) Aqui (quase) nada é como você pensa. [...] Não esqueça que está na Guatemala. [...] Dizem que em uma das barracas vendem cocaína e pedras de crack. Melhor não protestar. (Tradução nossa) romances e reafirmam uma prática violenta que se mantém no cotidiano nacional por gerações como uma organização social bem-sucedida e durável, conforme aponta o autor.

Além disso, mostram-se ao leitor as instituições sociais falidas, mas que ainda se sustentam dentro da sociedade guatemalteca atual como um sistema judiciário ultrapassado que ainda tem em suas bases a prerrogativa da pena de morte legal e ilegalmente ou um fracassado avanço tecnológico no qual nem sempre os elevadores dos prédios empresariais ou residenciais de luxo funcionam. Também se percebem as diferenças entre as classes sociais e os privilégios dos mais abastados, que podem se proteger com coletes à prova de balas e carros blindados (ou contratando guarda-costas, como em Los Sordos) e ainda podem monopolizar o poder político por todo um século na capital enquanto a população mais pobre sofre com a violência e o descaso diretamente.

Em Piedras encantadas (2001), Rey Rosa introduz a questão dos indígenas dentro da sociedade guatemalteca e como a atual Guatemala foi levantada às custas 
desta população escravizada por séculos. O primeiro parágrafo do capítulo 3 dessa narrativa é um exemplo disso:

La Reforma.

Paseo de la Reforma.

La despiadada reforma que abolió el derecho de los indígenas guatemaltecos a sus tierras comunales para que fueran convertidas en plantaciones de café, era conmemorada por el nombre de la ancha avenida por donde rodaban - avenida abierta, aplanada y pavimentada por los mismos indígenas cuyas tierras habían sido usurpadas por aquella reforma. (REY ROSA, 2014, p. 220) ${ }^{12}$

A ironia e a incongruência no trecho citado acima reforçam tanto a temática da violência quanto uma estrutura textual pautada nesta poética, pois, mais uma vez, a escolha do léxico trabalha para confirmar a ideia levantada. A avenida nomeada para comemorar uma reforma atroz para os indígenas é a mesma avenida que foi construída, aberta, aplanada e pavimentada por trabalhadores de origem indígena.

\footnotetext{
${ }^{12}$ A Reforma.

Paseo de la Reforma.

A impiedosa reforma que aboliu o direito dos indígenas guatemaltecos a suas terras comunais para que fossem convertidas em plantações de café, era comemorada pelo nome da larga avenida por onde rodavam avenida aberta, aplanada e pavimentada pelos mesmos indígenas cujas terras haviam sido usurpadas por aquela reforma. (Tradução nossa)
}

Desse modo, em Piedras encantadas (2001), mais uma vez o leitor não se pode deixar enganar pela aparência das belezas naturais existentes na região, mas deve atentar-se para os problemas que estão incrustados em um corpo social totalmente atingido pela violência e suas variantes.

Em outro início de capítulo, o narrador aponta para essa mesma quebra da normalidade, indicando a imagem ilusória que foi construída pelos arredores da cidade e remontando o passado que se reflete nas ruas e avenidas da capital da Guatemala:

[...] Bajó por la Sexta Avenida hacia el bulevar Liberación (conmemorativo del derrocamiento del primer intento de gobierno democrático en el istmo). [...] Dobló hacia las Américas: nuestra avenida de las Américas, <<que no tenía nada que envidiar a su homónima neoyorquina >> (ja, ja). Para el inspector, las Américas aludía también a la famosa Escuela de las Américas, en Carolina del Norte, donde algunos de los militares guatemaltecos más sanguinarios de la historia reciente habían recibido instrucción especial en técnicas de penetración en la sociedad civil, lavado de cerebros y tortura. A lo largo de esta avenida, en aquel bosquecillo de cipreses del Líbano en el amplio arriate central, aparecieron los primeros cadáveres de víctimas de las operaciones de limpieza político-social, más de treinta años atrás, recordaba el inspector. Apartó la mirada; una mujer demente, bastante joven, 
morena y muy sucia, se había acuclillado cerca de un viejo árbol de yuca, y se arremangó la falda para mostrar las nalgas y defecar. (REY ROSA, 2014, p. 245)

O excerto acima revela ao leitor abruptamente as condições históricas que foram tomadas como base para erguer este estado-nação centroamericano. As memórias que os lugares trazem ao inspetor são de um passado tenebroso e regido pela violência, seja ela fruto da guerra civil ou de governos autoritários anteriores a esse acontecimento.

Assim, em Piedras encantadas, a questão dos ataques à população sob as vestes de limpeza social aparece destacada nesta narrativa.

\footnotetext{
${ }^{13}$ [...] Desceu pela Sexta Avenida em direção ao bulevar Liberación (comemorativo da queda da primeira tentativa de governo democrático no istmo). [...] Virou em direção à avenida Américas: nossa avenida das Américas, <<que não tinha nada que invejar a sua homônima nova iorquina $>$ (ha, ha). Para o inspetor, las Américas aludia também à famosa Escola das Américas, na Carolina do Norte, onde alguns dos militares guatemaltecos mais sanguinários da história recente haviam recebido treinamento especial em técnicas de penetração na sociedade civil, lavagem cerebral e tortura. Ao longo desta avenida, naquele pequeno bosque de ciprestes do Líbano no amplo canteiro central, apareceram os primeiros cadáveres de vítimas das operações de limpeza político-social, mais de trinta anos atrás, relembrava 0 inspetor. Afastou o olhar; uma mulher demente, bastante jovem, morena e muito suja, havia agachado perto de uma velha árvore de mandioca, e subiu sua saia para mostrar as nádegas e defecar. (Tradução nossa)
}

Isso demonstra o quanto tais atos influenciaram e ainda permanecem fortemente ligados à estrutura social guatemalteca. Não é à toa que as narrativas de Rey Rosa escancaram, a partir dos retratos projetados e de suas características estruturais, a situação histórica, política, econômica e social da Guatemala. Também consegue-se compreender 0 sentimento de frustração em relação a propostas de melhorias em um futuro próximo.

Apesar de não serem temáticas novas, a maneira como são trazidas ao leitor é que apontam para uma estética diferente nas obras de Rey Rosa. A partir deste último trecho, por exemplo, nota-se como o narrador redireciona o olhar de seu leitor para aquilo que está oculto nas próprias estruturas do texto. Não é a imagem das avenidas que o inspetor está percorrendo que é importante, mas a história por trás delas que se torna relevante.

Além disso, o narrador faz questão de terminar o fragmento com uma cena nauseante na qual uma mulher defeca em um lugar público sem a menor preocupação. A caracterização da transeunte, juntamente com sua prática ao ar livre, 
também reforça uma desestabilização da leitura feita naquele momento pelo leitor, que acaba afastando seu olhar do texto assim como o fez a personagem, como um ato de repulsa.

Do mesmo modo, a conduta dessa mulher pode ser entendida como um ato de violência com o leitor, que mesmo com as imagens anteriores se surpreende com a última cena ao mesmo tempo em que é um ato hostil ou de afronta contra o próprio sistema que a violentou por anos ao não the proporcionar condições dignas de sobrevivência.

A presença dessa mulher demente dentro da cena narrada aumenta a sensação de naturalidade das ações repugnantes dentro do sistema social guatemalteco, pois as atrocidades históricas reveladas pelos pensamentos do inspetor realçam essa característica dentro do texto e é complementada pela prática da moça ao final.

Pensando no contexto da narrativa, menciona-se que a naturalidade em se praticar atos violentos e inconsequentes está atrelada ao cotidiano da cidade onde um motorista prefere não parar para socorrer um menino atropelado por ele próprio e na qual também a exploração de mão de obra indígena levantou monumentos pela cidade e construiu suas vias ou a memória retorcida dentro dos nomes das ruas e avenidas mais importantes da cidade.

Assim, a brutalidade torna-se natural dentro dos cenários narrados, pois as personagens convivem com ela constantemente. O leitor acaba se surpreendendo com a capacidade de as personagens sobreviverem a essas práticas tão concretas de violência plena.

Neste sentido, não se poderia considerar uma banalização da violência, mas um processo de naturalização dos elementos que geram a violência dentro do plano ordinário, pois a violência, que deveria ser considerada exceção dentro do nível cotidiano, está distribuída dentro dos cenários apresentados.

Rey Rosa apresenta em seus textos, desse modo, uma desestabilização do plano concreto e da realidade a partir de um jogo narrativo que irrompe a estrutura textual com componentes geradores de uma instabilidade violadora daquilo que é esperado pelo leitor. $O$ guatemalteco

experimenta 
desequilibrar a percepção no momento da leitura com quebras abruptas da normalidade conhecida na própria narrativa. Assim, a naturalização de fatos violentos dentro do panorama narrativo supostamente equilibrado causa um impacto àquele que lê seus textos. O seguinte trecho presente em Piedras encantadas reflete esta ideia:

[...] la gente paseaba por el arriate central; los niños de la calle que vendían chicles 0 rosas 0 mendigaban; los vendedores de coca; los informantes de las diferentes policías (nacionales, privadas $y$, hoy en día, también internacionales); las familias, que se movían en grupo, las sirvientas en día libre que se ocultaban tras los árboles con sus ávidos enamorados; los vendedores de globos o algodón de azúcar, de matracas, poporopos, perros calientes, tamales, enchiladas y distintas clases de atol. A pocos metros de la plaza de Colombia, el inspector estacionó el BMW y apagó el motor.

[...] Aquella mujer que vendía jabones podía ser confidente de la 2 - la temible Dirección de Inteligencia Militar - pero no estaba seguro. Además de informantes, había varios guardaespaldas (que solían ser agentes dobles) haciendo de niñeras para los hijos de sus jefas, que aguardaban cerca de allí en automóviles con vidrios polarizados. (REY ROSA, 2014, p. 246) ${ }^{14}$

\footnotetext{
14 [...] as pessoas passeavam pelo canteiro central; os meninos de rua que vendiam chicletes ou rosas ou mendigavam; os vendedores de coca; os informantes das diferentes polícias (nacionais, privadas e, atualmente, também internacionais); as famílias, que se movimentavam em grupo, as empregadas de folga que se escondiam atrás das árvores com seus ávidos namorados; os vendedores de balões ou algodão doce, de matracas, pipocas, cachorros quentes,
}

Neste fragmento, convivem em plena harmonia personagens da esfera comum como famílias reunidas, vendedores ambulantes e namorados apaixonados, com personagens que representam algum tipo de violência, como a miséria pela presença dos meninos de rua que mendigavam e o narcotráfico pela figura dos "vendedores" de coca. Também estão presentes os agentes policiais de diferentes estirpes, os informantes que trabalham para quem paga mais e, por último, os guarda-costas fazendo papel de babás para suas chefas enquanto estas ficam escondidas em seus carros com vidros enegrecidos.

A cena é descrita com um equilíbrio entre as figuras que destoam do comum, pois se aceitam diferentes classes de personagens, independente de índole e condutas, para compor esse cenário. A existência em

tamales, enchiladas e diferentes tipos de atol. A poucos metros da praça Colômbia, o inspetor estacionou o BMW e desligou o motor.

[...] Aquela mulher que vendia sabões podia ser confidente da 2 - a temível Direção de Inteligência Militar - mas não tinha certeza. Além de informantes, havia vários guardacostas (que costumavam ser agentes duplos) fazendo-se de babás para os filhos de suas chefes, que aguardavam próximo dali em automóveis com vidros polarizados. (Tradução nossa) 
equilíbrio dessas figuras causa uma quebra na experiência de narrativa do leitor porque a violência está alinhada aos padrões cotidianos do que se está sendo narrado. Dessa forma, é natural que no romance a violência apareça sem 0 questionamento de outras personagens, pois apenas existe a conformidade na convivência com elementos propulsores da brutalidade.

Todos esses elementos sistematizadores presentes neste cenário contribuem para a composição de um jogo narrativo que frequentemente testa o leitor dentro de seus níveis de conhecimento da narrativa e até onde ela pode chegar com essa estrutura. $O$ narrador aventura-se mostrando ao leitor que sua teoria inicial de aparências enganadoras é válida e não pode ser refutada a partir dos próprios elementos presentes em sua narrativa, pois elabora cenários desestabilizadores e apresenta personagens que põem em dúvida a percepção e a aceitação do leitor diante das características iniciais propostas para criá-los.

Dessa maneira, não se trata somente do fato de esconder sentimentos e ações sob uma máscara superficial para o núcleo social em que se vive e almeja benefícios, mas do fato de evidenciar a natureza das personagens a partir de mecanismos que desestabilizam tanto a narrativa quanto o leitor. Com isso, engana-se o leitor para que seja construída a narrativa desejada e sem necessidade de retratação, pois quem lê acaba se tornando mais uma personagem essencial para a narrativa: aquele que é impactado e, consequentemente, ludibriado pelo que está sendo narrado.

A própria figura do menino Silvestre é um caso particular, pois está involucrada a diferentes teorias que, a princípio, não compõem linearmente uma ideia clara e lógica. Ao lado da imagem de um filho adotivo estão a suspeita de um atropelamento proposital como vingança, um suposto envolvimento dos pais no tráfico de crianças, uma possível presença de membros da família verdadeira da criança e até a percepção de mundo de Silvestre frente à nova vida na Guatemala e a violência que o rodeia desde a Bélgica até seu cotidiano na capital guatemalteca.

Em um trecho após o atropelamento do menino o narrador 
aponta as ações de Rastelli para ajudar Silvestre a fugir do Hospital Militar:

El padre adoptivo de Silvestre tenía muchas deudas (en dinero y en especie) que liquidar, y alguna que otra que cobrar. Era posible que uno de sus acreedores, o uno de sus deudores, hubiera intentado secuestrar a Silvestre - 0 simplemente hacerle daño, a modo de aviso o venganza. $O$ que Barrondo, agobiado por sus obligaciones, hubiera decidido causar la muerte de Silvestre, parar cobrar un seguro de vida cuyo único beneficiario era él. (REY ROSA, 2014, p.274-275) ${ }^{15}$

\section{É interessante destacar que}

todas as resoluções pensadas por Rastelli para 0 atropelamento do garoto envolvem a violência de alguma maneira. Também vale ressaltar que Silvestre está colocado dentro de outros ambientes que incitam a violência à sua própria figura, pois ele pode estar envolvido com o tráfico de crianças, além de ser uma criança adotada e ter aparentemente sofrido maus tratos tanto no orfanato em Bruxelas na Bélgica quanto uma

${ }^{15} \mathrm{O}$ pai adotivo de Silvestre tinha muitas dívidas (em dinheiro e em espécie) que liquidar, e uma ou outra que cobrar. Era possível que um de seus credores, ou um de seus devedores, tivesse tentado sequestrar Silvestre - ou simplesmente fazer-lhe mal, a modo de aviso ou vingança. Ou que Barrondo, sobrecarregado por suas obrigações, tivesse decidido causar a morte de Silvestre, parar cobrar um seguro de vida cujo único beneficiário era ele. (Tradução nossa) negligência por parte de seus pais guatemaltecos, que estavam mais preocupados com a oferta material dada ao menino que o afeto familiar.

Acrescidos a tais ideias, encontram-se os pensamentos do próprio garoto, que acredita, por exemplo, que o guarda-costas e motorista da família quer assassiná-lo e que a enfermeira do hospital em que ele se encontrava em recuperação era na verdade um robô pela forma mecânica e pouco natural de seus gestos, o que também agrega um caráter de desumanização quanto ao tratamento recebido pelo garoto.

A solução encontrada por Rastelli para salvar o menino da agressividade que envolve sua família adotiva guatemalteca é também ferramenta propagadora de outra violência: fugir do hospital e viver com o grupo de meninos de rua chamados de Piedras Encantadas. A opção é aceita por Silvestre porque ele não se enxerga como um membro pertencente à sociedade em que vive: Silvestre experimentó un intenso deseo de mirarse en un espejo. Era tan distinto de todos - de Faustino e lleana, de las caras que veía en la televisión, de los niños del colegio o de 
la calle, y de aquella enfermera [...] (REY ROSA, 2014, p. 271) ${ }^{16}$. Mesmo não se vendo parecido com os meninos de rua o garoto prefere a companhia destes que a de seus pais abastados.

Assim, Silvestre não escapa do universo violento que o rodeia, mas apenas modifica a sua experiência de violência, pois começa a viver nas ruas com as outras crianças, sob os cuidados da miséria e da fome, da perseguição dos policiais que rondam as praças e até mesmo dos agentes duplos e detetives que usam essas crianças como seus informantes em certas situações, como é o caso do próprio Rastelli. Acusados de propagar o medo e a violência pelas praças e ruas centrais da capital guatemalteca, a gangue Piedras Encantadas é a que mais sofre dentro de um sistema social que fomenta a violência e os exclui socialmente, deixando-os à margem de qualquer projeto de ascensão social.

A narrativa aponta que é um grupo de crianças entre cinco e dez

\footnotetext{
${ }^{16}$ Silvestre experimentou um intenso desejo de olhar-se em um espelho. Era tão diferente de todos - de Faustino e lleana, das caras que via na televisão, das crianças do colégio ou da rua, e daquela enfermeira [...] (Tradução nossa)
}

anos, que vive nas ruas da Cidade da Guatemala e tentam sobreviver roubando ou servindo como informantes. Além disso, muitos nem se conhecem entre si e aqueles que se conhecem convivem cercados pela violência do espaço em que se encontram:

\begin{abstract}
- ¿Y a vos qué te pasó? - le preguntó el Tarántula a Silvestre.

- Me atropellaron. - Les mostró la cadera desollada. - ¿Y a vos?

- Esos policías - dijo el Malrollo, y se levantó la camiseta para enseñar varios moretones - . Me agarraron oliendo a pegamento y por eso diz que me dieron verga. Jovito, enseñale el plomazo.

Jovito les enseñó la herida de bala que tenía en el pecho, y los niños se movieron para ver la cicatriz más de cerca.

- Le traté de robar a un señorón. Estaba armado, y al darse cuenta de que quería sacarle la cartera, me metió un tiro. (REY ROSA, 2014, p. $280)^{17}$
\end{abstract}

O fragmento acima demonstra a violência sofrida pelo grupo de crianças reconhecido como Piedras

\footnotetext{
17. E o que aconteceu com você? - Ihe perguntou Tarântula a Silvestre.

- Me atropelaram. - mostrou-lhes a cintura esfolada. - E com você?

- Esses policiais - disse Malrollo, e levantou a camiseta para mostrar vários hematomas-. Me pegaram cheirando cola e por isso que me deram uma surra. Jovito, mostra a sua cicatriz de tiro.

Jovito lhes mostrou a ferida de bala que tinha no peito, e os meninos se mexeram para ver a cicatriz mais de perto.

- Tratei de roubar um velhote. Estava armado, e ao perceber que eu queria tirar sua carteira do bolso, me deu um tiro. (Tradução nossa)
} 
Encantadas. Apesar de serem considerados violentos, este trecho retrata, na realidade, que quem é violentado pelo sistema social excludente são esses meninos de rua, que reagem a essa estrutura agressiva que Ihes é apresentada da mesma maneira em que são acometidos por ela. É a reação em cadeia daqueles que são desprivilegiados dentro de uma organização social atroz com precedentes históricos.

Silvestre é aceito no grupo não só pelo fato de ter sofrido algum tipo de violência física, como o seu atropelamento, mas também porque se encaixa nos padrões de exclusão social por ser adotado e ter um histórico de violência em sua vida. Do mesmo modo, as outras crianças do bando mostradas ao leitor apresentam traços da violência cotidiana praticada pelo sistema social através de figuras marcadas como a polícia e os civis armados dentro da Guatemala. Paradoxalmente, 0 menino belga prefere viver dentro desta esfera marginal que a sociedade the oferece que estar em um círculo familiar e burguês que não lhe é amistoso nem saudável.
Essa contradição apresentada abre a possibilidade de se considerar que a violência sofrida na infância, na Europa assim como na Guatemala, proporciona um sentido de linearidade atrelada a uma lógica absurda, traço constante nos textos de Rey Rosa. A localidade não importa, pois a violação dos direitos pelo sistema social em que o menino está inserido se faz presente a todo momento: primeiro como órfão; depois, como produto de um possível tráfico de pessoas que ocorre entre os dois continentes e, por fim, como vítima de um atropelamento com características de vingança contra seus pais adotivos ou acerto de contas. Não parece existir escapatória para Silvestre da violência que the é conferida.

Para poder sobreviver ou ascender dentro da sociedade guatemalteca, Silvestre, deverá encaixar-se nos moldes estabelecidos neste cotidiano pelo âmbito da violência em que se encontra e que lhe é imposta pela estrutura organizacional daquela sociedade. Silvestre se adapta ao rejeitar as regalias de uma vida de classe média alta para viver na miséria com seus amigos de rua. 
É interessante destacar neste ponto a ideia de que a violência se compõe como uma unidade, um traço marcante da identidade das personagens dos romances de Rey Rosa como se fosse o elo que as une nesse universo naturalmente violento. Para que possam pertencer à esfera ficcional apresentada, elas devem possuir a violência como característica que as faça fazer parte desse padrão já estabelecido. Em um mecanismo bem engendrado, as personagens são as peças ligadas ao eixo central, que é a violência sofrida/praticada/vivenciada/compartilh ada.

Dessa maneira, mais uma vez a frase contida no prefácio de Piedras Encantadas aponta não só para o retrato da Guatemala feito pelo autor no romance, mas evidencia as características paradoxais das personagens contidas nas três obras analisadas em que a aparência inicial é posta em xeque pelas ações e situações apresentadas ao longo dos enredos.

\section{Considerações finais}

Em Piedras encantadas (2001), entende-se que as personagens se conectam por dois fios narrativos: primeiro, a sua experiência com a violência e aceitação desta em suas vidas ou daqueles que as cercam e, em segundo, as ligações de seus cotidianos com alguém que possui alguma proximidade ou relação com o atropelamento de Silvestre. Joaquín se vincula ao atropelamento ao aceitar que seu amigo pratique um ato de violência e fuja logo em seguida; Elena, por conhecer Joaquín e trabalhar no jornal em que se está investigando 0 atropelamento do garoto; Rastelli, por ser contratado para investigar o caso; lleana e Faustino, por serem os pais adotivos de Silvestre; o cuidador dos cavalos, por ter aceitado dinheiro e estar envolvido diretamente com 0 atropelamento e as crianças de rua por serem informantes ao mesmo tempo em que se tornam a segunda família do garoto.

Com isso, personagens inicialmente aleatórios se unem para construir a narrativa a partir de um acontecimento pautado em uma atitude violenta. Em Piedras Encantadas (2001), o leitor é conduzido por caminhos que evidenciam uma narrativa baseada na 
estética da violência, a partir das imagens presentes no texto e na própria construção do romance proposta pelo autor guatemalteco.

Além disso, naturaliza-se a violência para que ela seja aceita dentro do plano de construção da própria narrativa e como forma de desestabilização do leitor desacostumado com um projeto de concretude pautado nesse espaço agressivo e violento.

As construções imagéticas da violência no romance estudado proporcionam ao leitor vislumbrar uma estrutura textual pautada também no sensorial e descritivo em que a violência se torna um meio para se perceber e entender muitas vezes 0 retrato exposto da Guatemala atual.

Em Piedras Encantadas (2001), o leitor fica desprovido de um referencial de justiça a que teoricamente e tradicionalmente está acostumado. Não há um herói por quem torcer, mas personagens repletos de falhas e defeitos para serem discutidos e compreendidos dentro de seu universo. É uma violência e a representação de uma realidade traumática, ocasionadas por questões históricas, refletidas nos retratos da Guatemala e na denúncia sempre presente, mas também é uma violência cotidiana que aparece para questionar as suas raízes dentro da estrutura da sociedade retratada.

\section{Referências bibliográficas}

CORTEZ, Beatriz. Estética del cinismo: Pasión y desencanto en la literatura centroamericana de posguerra. Guatemala: FyG editores, 2010.

CUEVAS MOLINA, Rafael. De Banana Republics a repúblicas maquileras. San José: EUNED, 2012.

DORFMAN, Ariel. Imaginación y violencia en América Latina. Barcelona: Anagrama, 1972.

ESCAMILLA, José Luis. El protagonista en la novela de posguerra centroamericana: desterritorializado, híbrido y fragmentado. El Salvador: Ed. Universidad Don Bosco, 2011.

MACKENBACH, Werner; ORTIZ WALLNER, Alexandra. De (formaciones): violencia y narrativa en Centroamérica.

Revista Iberoamericana, 32, p. 81-97, 2008.

ORTIZ WALLNER, Alexandra. El arte de ficcionar: la novela contemporánea en Centroamérica. Madrid: Iberoamericana Editorial Vervuert, 2012.

ORTIZ WALLNER, Alexandra. Poéticas de la violencia en Centroamérica: literatura y nuevas sensibilidades. In: MACKENBACH, Werner; MAIHOLD, Günther (orgs.). La transformación de la violencia en América Latina. Guatemala: F\&G Editores, 2015. 
ORTIZ WALLNER, Alexandra. Trazar un Itinerario de Lectura: (Des) Figuraciones de la Violencia en una Novela Guatemalteca". Revista Inter Sedes, 6, p. 135-145, 2003.

REY ROSA, Rodrigo. Imitación de Guatemala: cuatro novelas breves. Ciudad de México: Alfaguara, 2014.
SCHØLLHAMMER, Karl Erik. Cena do crime: violência e realismo no Brasil contemporâneo. Rio de Janeiro: José Olympio, 2013. 